(C2017, Elsevier. Licensed under the Creative Commons Attribution-NonCommercialNoDerivatives 4.0 International http://creativecommons.org/about/downloads

(9) $\odot \Theta \Theta$ 


\title{
Spatial (bio)accumulation of pharmaceuticals, illicit drugs, plasticisers, perfluorinated compounds and metabolites in river sediment, aquatic plants and benthic organisms
}

\author{
John L. Wilkinson ${ }^{1,2^{*}}$, Peter S. Hooda ${ }^{1}$, Julian Swinden ${ }^{3}$, James Barker ${ }^{3}$ and Stephen \\ 3 \\ Barton \\ ${ }^{1}$ School of Natural and Built Environments, Kingston University London, Kingston-upon-Thames, Surrey, UK \\ 2 Environment Department, University of York, York, UK, ${ }^{3}$ School of Life Sciences, Pharmacy and Chemistry, Kingston \\ University London, Kingston-upon-Thames, Surrey, UK \\ *Corresponding Author: john.wilkinson@york.ac.uk
}

\begin{abstract}
Organic contaminants such as pharmaceuticals, personal care products (PPCPs) and other emerging contaminants (ECS) are known to persist in the aquatic environment and many are indicated as endocrine, epigenetic, or other toxicants. Typically, the study of PPCPs/ECs in the aquatic environment is limited to their occurrence dissolved in river water. In this study, accumulation and spatial distribution of thirteen PPCPs/ECs were assessed in aquatic sediment $(n=23)$, periphyton (biofilm, $n=8)$, plants Callitriche $\mathrm{sp} .(\mathrm{n}=8)$ and Potamogeton $\mathrm{sp}$. $(n=7)$ as well as amphipod crustaceans (Gammarus pulex, $n=10)$ and aquatic snails (Bithynia tentaculata, $n=9)$. All samples $(n=65)$ were collected from the Hogsmill, Blackwater and Bourne Rivers in southern England. Targeted PPCPs/ECs included pharmaceuticals, plasticisers, perfluorinated compounds, illicit drugs and metabolites. Extraction from solid matrices occurred using ultrasonic-assisted extraction followed by an in-house validated method for solid-phase extraction and subsequent liquid-chromatography tandem massspectrometry. Field-derived bioconcentration-factors and biota-sediment accumulationfactors were determined for all studied biota. Residues of studied contaminants were found in all sediment and biota. Concentrations of contaminants were generally higher in biota than sediment. Evidence suggests that the studied aquatic plants may effectively degrade bisphenol-A into its main transformation product hydroxyacetophenone, potentially mediated by cytochrome p450 and internalisation of contaminants into the cellular vacuole. A positive association between both hydrophobicity and PFC chain length and contaminant accumulation was observed in this work. Only PFCs, plasticisers and HAP were classified as either 'bioaccumulative' or 'very bioaccumulative' using BCF criteria established by guidelines of four governments. Contaminants appeared to be differentially bioaccumulative in biota, indicating there may be a need for a species-specific BCF/BSAF classification system. These data form a detailed accounting of PPCP/EC fate and distribution in the aquatic environment highlighting accumulation at lower trophic levels, a potential source for higher organisms.
\end{abstract}

\section{Conflict of Interests}

Nothing to declare 


\subsection{Introduction}

Pharmaceuticals, personal care products (PPCPs) and other emerging contaminants (ECs) were known to contaminate sewage treatment work (STW) effluent (Halling-Sørensen et al., 1998) and receiving streams and rivers (Kolpin et al., 2002) since the late 1990s and are suggested to affect the health of non-target organisms in the aquatic environment. Furthermore, PPCPs/ECs are indicated to affect biological mechanisms such as endocrine disruption (Vajda et al., 2008; Patisaul et al., 2009; Vajda et al., 2011) and gene expression/epigenetics for up to multiple generations (Bhandari et al., 2015; Wilkinson et al., 2016a). Although nearly every chemical used by humans on a day-to-day basis has been detected in water, concentrations of such organic pollutants are rarely evaluated and little is known of their occurrence in primary producers and benthic organisms such as aquatic plants, biofilm/periphyton, snails and amphipod crustaceans (Du et al., 2015; Huerta et al., 2016; Xie et al., 2017). Such matrices may be a sink for PPCPs/ECs in the aquatic environment and a potential source of the contaminants to higher trophic-level organisms (Lagesson et al., 2016; Xie et al., 2017). Benthic aquatic organisms such as the Faucet Snail Bithynia tentaculata and amphipod crustacean Gammarus pulex are known to feed on primary producers such as aquatic plants, substrate algae and biofilm/periphyton which may contain trace amounts of potentially bioactive contaminants. Accumulation of organic contaminants in sediment may also affect contaminant concentrations in primary producers such as aquatic plants, biofilm/periphyton and benthic organisms.

Here the partition and bio/accumulation of 13 representative markers of anthropogenic contamination in the aquatic environment were assessed in sediment and five understudied organisms ( $n=65$ total). Studied organisms included primary producers Callitriche sp. (Water Starwort plant), Potamogeton sp. (Pondweed plant) and biofilm/periphyton as well as benthic organisms B. tentaculata (Common Mud Snail) and G. pluex (amphipod crustacean). These organisms were selected for four specific reasons: a) they are all widely present in English rivers receiving STW effluent outfalls; b) are previously under-studied; c) are representatives of two steps of the lower aquatic trophic-ladder (i.e., are either primary producers or low-level consumers); and d) are potentially exposed to PPCPs/ECs via both water and diet. B. tentaculata was specifically chosen as it additionally filter-feeds using its 
gills to collect suspended algae which is then condensed, excreted via the exhalant siphon and subsequently consumed (Jokinen, 1992). Selected contaminants (see Table 1 in Wilkinson et al., 2017b) included pharmaceuticals, plasticisers, perfluorinated compounds (PFCs), illicit drugs and metabolites. Concentrations of studied analytes were evaluated at each sampling location as a part of a concurrent investigation (see Wilkinson et al., 2017a). Specific aims of this work include:

a) Establishment of a standardised approach for the development and optimisation of extraction methodologies which are then used to develop individual protocols for the extraction of PPCPs/ECs from our target organisms;

b) Assessment of the occurrence and spatial distribution of 13 selected markers of anthropogenic contamination (i.e., PPCPs/ECs) in sediment and five under-studied primary producers and low trophic-level benthic consumers (Callitriche sp., Potamogeton sp., biofilm/periphyton as well as B. tentaculata and G. pluex;

c) Calculation of previously un-established field-based bioconcentration (BCF) and biotasediment accumulation factors (BSAF); and

d) Examination of the occurrence of both parent compounds and metabolites in various environmental matrices to provide some insight into the transformation of these chemicals in lower trophic level organisms.

\subsection{Study Area}

Selected rivers included the Hogsmill River (Greater London), Chertsey Bourne River and the Blackwater River (see Figure 1 in Wilkinson et al., 2017b). Rivers received inputs from a total of five sewage treatment works (STWs) effluent outfalls (see Figure 1 in Wilkinson et al., 2017b): 3 discharging into the Blackwater River and one each into the Hogsmill and the Chertsey Bourne Rivers. The studied rivers were selected based on feasibility of sample collection and their location (i.e., both urban and rural catchments). Sediment was collected along the course of all three rivers (starting at headwaters in the Hogsmill and Blackwater) while aquatic plants and benthic organisms were collected from the Hogsmill and Blackwater Rivers only (see Figure 1 in Wilkinson et al., 2017b). To assess the spatial distribution of selected contaminants entering sediment and biota via STW effluent, samples were collected $50 \mathrm{~m}$ upstream from effluent outfalls, $50 \mathrm{~m}$ downstream of 
respective STW effluent outfall as well as $250 \mathrm{~m}$ and $1000 \mathrm{~m}$ downstream from the outfalls (see Figure 1 in Wilkinson et al., 2017b).

Concentrations of targeted contaminants were quantified in the dissolved phase of water at each biota collection point three to four separate times (depending on site accessibility) as part of a separate, complementary study (Wilkinson et al., 2017a). This method allows for more accurate calculation of field-based BCF and BSAF-values as the inherent variability of grab sampling over time periods (e.g., Jiang et al., 2014) is, to some extent, corrected. A summary of mean contaminant concentrations in water can be found in Table 2 of the complementary Data in Brief article for this work (Wilkinson et al., 2017b). Concentrations of target contaminants were assessed using the method presented by Wilkinson et al. (2016b) based on a previously in-house validated method for high performance liquid chromatography-tandem mass spectrometry (HPLC-MS/MS).

\subsection{Materials and Methods}

Compounds selected for study included pharmaceuticals: ethinylestradiol, acetaminophen and diclofenac, illicit drugs and metabolites: methamphetamine, amphetamine and benzoylecgonine (metabolite of cocaine), plasticisers: bisphenol-S (BPS), bisphenol-A (BPA) and its biotransformation product 4'-hydroxyacetophenone (HAP), perfluorinated compounds: PFOA, PFOS, PFNA, and PFBS, and deuterated internal standards: BPA-D16, acetominophen-D4 and methamphetamine-D5. All compounds were purchased from Sigma Aldrich (Gillingham, Dorset, U.K.). Strata-X $33 \mu \mathrm{m}$ polymeric reversed phase $200 \mathrm{mg} / 6 \mathrm{~mL}$ SPE cartridges were purchased from Phenomenex (Macclesfield, Cheshire, U.K.). A Phenomenex Kinetex $2.6 \mu \mathrm{m}$ C18 $150 \times 2.1 \mathrm{~mm}$ chromatography column using a SecurityGuard ULTRA UHPLC C18 2.1mm guard column was purchased from Phenomenex (Macclesfield, Cheshire, U.K.). Whatman GF/F glass microfiber filters (diameter $47 \mathrm{~mm}$, pore size $0.7 \mu \mathrm{m}$ ) were purchased from Fisher Scientific (Loughborough, Leicestershire, U.K.). Analyte extractions were conducted in a 100W heated CamLab S120H ultrasonication bath (Cambridge, U.K.).

\subsection{Sample Collection and Preparation}


Detailed sample collection methods can be found in the complementary Data in Brief article for this work (Wilkinson et al., 2017b). Briefly, sediment samples were collected as a composite sample from respective river sampling point (i.e., three samples collected and pooled at each location) using a Van Veen grab sampler. Sediment was then loosely covered with acetonitrile washed aluminium foil and air-dried for $72 \mathrm{~h}$ in the dark at ambient temperature in the lab $\left(21.3 \pm 0.4^{\circ} \mathrm{C}\right)$. Dry sediment was then sieved to a particle diameter $<750 \mu \mathrm{m}$ and stored at $-20^{\circ} \mathrm{C}$ in the dark until extraction.

Periphyton (biofilm) was scraped from river stones using a solvent rinsed metal razor blade while aquatic plant samples (Callitriche sp. and Potamogeton sp.) were picked from the base of the plant at respective locations to collect both stems and leaves. Upon return to the lab, all biofilm and aquatic plant samples were loosely covered with acetonitrile-washed aluminium foil and air-dried for $72 \mathrm{~h}$ in the dark at ambient temperature in the lab (21.3 \pm $0.4^{\circ} \mathrm{C}$ ). Dry material was then powdered using either an acetonitrile-washed mortar and pestle (for biofilm) or a Bel-Art Products Micromill (Pequannock, NJ, USA) for plant samples.

The amphipod crustaceans ( $G$. pluex) and snails (B. tentaculata) were collected using a benthic sampling net. Snails were removed from their shells prior to drying. Both snails and amphipod crustacean were frozen at $-80^{\circ} \mathrm{C}$ and freeze dried prior to homogenisation. Freeze drying was selected here due to an inability to adequately air dry the tissue. Prior to extraction, all samples were stored in the dark at $-20^{\circ} \mathrm{C}$.

Although ethical approval was not required for work with invertebrates, care and thought were put into the ethical sacrifice of the organisms. To avoid possible analyte loss by liquid or gas sacrifice, an acetonitrile-washed pin was inserted into each organism to achieve a rapid sacrifice.

\subsection{Extraction of Target Analytes from Solid Matrices}

Analysis of contaminants accumulated in solid matrices first requires an extraction step before ultimate quantitative analysis. Techniques such as microwave, pressurised solvent, ultrasonic-assisted and Soxhlet extraction have been used to extract PPCPs/ECs from various 
solid matrices (e.g., USEPA, 2007; Pico, 2013; Albero et al., 2015; Vazquez-Roig and Pico, 2015). Here, US EPA method 3546 for microwave extraction, Soxhlet extraction based on Wang et al. (2010) and ultrasonic-assisted extraction based on Martin et al. (2010) were all tested for recovery of the 13 PPCPs/ECs selected in this work. Success of each technique was judged based on recovery of all 13 studied contaminants from respective matrix spiked to $100 \mathrm{ng}$ of each analyte/ g dry weight (dw). Ultimately, ultrasonic-assisted extraction (UAE) followed by solid phase extraction showed the highest recoveries (median $52.3 \%$ for sediment) and hence was selected for this work (median recovery by microwave assisted and soxlet extraction were $14.2 \%$ and $21.7 \%$ respectively for sediment). To improve analyte recovery using $U A E$, a standardised approach was developed here to optimise extraction protocols for solid matrices. Optimised parameters included temperature, extraction duration, and extraction solvent composition/volume for each matrix: sediment, plants, biofilm, snails and amphipod crustaceans.

\subsubsection{Standardisation of Extraction Optimisation}

Here, a standardised protocol for optimising the extraction of target PPCPs/ECs was developed and applied to five matrices. The developed optimisation protocol may be applied to other matrices and compounds. Resulting extraction methods utilised ultrasonicassisted solvent extraction (UAE) using a CamLab S120H ultrasonication bath followed by solid phase extraction (SPE). Five overarching variables were identified for optimisation: extraction solution (i.e., ratio of solvents), acidification of the extraction solution, volume of extraction solution, duration of sonication, and temperature of sonication. Each overarching variable was optimised individually over five sequential steps with the resulting extraction protocol further developing at each step:

Step 1: Optimisation of extraction solution

Step 2: Optimisation of extraction solution acidification

Step 3: Optimisation of extraction solution volume

Step 4: Optimisation of sonication duration

Step 5: Optimisation of sonication temperature 
Optimisation was assessed using spiked matrix recovery at a standard concentration of 100 ng respective analyte/ $g$ respective dry matrix (i.e., at or near maximum expected concentrations in real samples). All matrices were washed three times with 50:50 acetonitrile: acetone $(\mathrm{v} / \mathrm{v})$ before any optimisation analysis occurred to minimise potential background concentrations of target analytes. Prior to the optimisation of each variable, respective matrix was homogenised then spiked with all analytes to a concentration of 100 ng analyte/ g dw matrix and allowed to dry at room temperature for $3 \mathrm{~h}$. No significant difference (i.e., within the range of reproducibility) in recoveries was observed when spiked matrix was left at room temperature in the dark for up to $36 \mathrm{~h}$ prior to extraction. Hence, 3 h post spike drying time was deemed sufficient to produce reference material for each matrix. Recovery was assessed by extracted ion chromatogram peak abundance relative to that of a known standard at the same concentration which did not undergo UAE-SPE.

It should be noted that the mass of spiked matrix used for each extraction during optimisation was standardised for each respective matrix and equal to the mass of field sample used in each extraction protocol (Table 1). The mass of each matrix to be extracted was decided as the maximum amount of material which could be feasibly collected, prepared, and managed throughout the extraction protocol without sample loss given potential analytical or equipment restraints (i.e., extraction vessel size, storage restraints, etc.).

Three replicates were used to assess each variable within respective optimisation steps. For example, when optimising the volume of extraction solution used for the extraction of PPCPs/ECs from sediment (Step 4), three replicates of $1 \mathrm{~g}$ spiked sediment were extracted in $10 \mathrm{~mL}$ ( $\mathrm{n}=3$ replicates), $15 \mathrm{~mL}$ ( $\mathrm{n}=3$ replicates), $20 \mathrm{~mL}$ ( $\mathrm{n}=3$ replicates), $25 \mathrm{~mL}$ ( $\mathrm{n}=3$ replicates) and $30 \mathrm{~mL}$ ( $\mathrm{n}=3$ replicates) extraction solution. Recoveries were averaged between replicates and used to determine ideal extraction conditions for each optimisation step.

A detailed description of the final extraction protocols for each matrix is provided in Wilkinson et al. (2017b) and a summary is found in Table 1. Briefly, a standardised mass (e.g., $1 \mathrm{~g}$ of sediment, $500 \mathrm{mg}$ plant material, Table 1) of dry sample was added to $20 \mathrm{~mL}$ of a 
matrix-optimised proportion of acetonitrile:methanol and subjected to ultrasonication at $40-45^{\circ} \mathrm{C}$ (matrix-dependent) for $20 \mathrm{~min}$. Mean spiked recoveries ranged from $62 \%$ from biofilm to $76 \%$ from sediment (Table 1). Separation of solid and liquid components of the extract was achieved using vacuum filtration through a GF-F glass mircofibre filter prewashed three times in methanol:acetonitrile $(50: 50, \mathrm{v} / \mathrm{v})$. The extract was then reduced to approximately $1.5 \mathrm{~mL}$ by rotary evaporation and diluted with $80 \mathrm{~mL} \mathrm{HPLC}-\mathrm{H}_{2} \mathrm{O}(<2 \%$ solvent in diluted solution) prior to being subjected to solid phase extraction (SPE) and ultimate HPLC-MS/MS analysis.

\subsection{Quantification of 13 Selected PPCPs/ECs Using Solid Phase Extraction (SPE) Followed by Liquid Chromatography-Tandem Mass Spectrometry (LC-MS/MS)}

The ultimate SPE-HPLC-MS/MS method used here was previously optimised and validated in-house (Wilkinson et al., 2016b). Full and detailed SPE-HPLC-MS/MS protocol and method quality control measures used in this work are described by Wilkinson et al. (2016b).

Briefly, SPE was carried out using Phenomenex Strata-X cartridges preconditioned with $3 \mathrm{~mL}$ 50:50 acetonitrile/acetone (v/v), washed with $3 \mathrm{~mL} \mathrm{HPLC}$-grade $\mathrm{H}_{2} \mathrm{O}$ and loaded at a rate of $5 \mathrm{~mL} / \mathrm{min}$ and dried for 20 min under vacuum. Elution occurred with $2 \times 7 \mathrm{~mL}$ aliquots of 50:50 acetonitrile/acetone $(\mathrm{v} / \mathrm{v})$ at a rate of $1 \mathrm{~mL} / \mathrm{min}$. Extracts were evaporated to dryness using rotary evaporation and reconstituted with $1 \mathrm{~mL}$ of $80: 20 \mathrm{HPLC} \mathrm{H}_{2} \mathrm{O}$ /acetonitrile $(\mathrm{v} / \mathrm{v})$ spiked with internal standards to $25 \mathrm{ng} / \mathrm{mL}$ prior to HPLC-MS/MS analysis.

HPLC separation was achieved for all compounds and extracts from all matrices on a Phenomenex Kinetex $2.6 \mu \mathrm{m}$ C18 $150 \times 2.1 \mathrm{~mm}$ chromatography column using a SecurityGuard ULTRA UHPLC C18 $2.1 \mathrm{~mm}$ guard column. Merck Millipore LiChrosolv hypergrade acetonitrile (Darmstadt, Germany) and Honeywell Burdick \& Jackson HPLCgrade water (Muskedon, MI, USA) were used for all HPLC-MS/MS. A flow rate of $0.2 \mathrm{~mL} / \mathrm{min}$ with a solvent gradient from 80:20 $\mathrm{H}_{2} \mathrm{O}$ /acetonitrile $(\mathrm{v} / \mathrm{v})$ to $35: 65 \mathrm{H}_{2} \mathrm{O} /$ acetonitrile $(\mathrm{v} / \mathrm{v})$ over 15 min was used with a 5-min equilibration time between runs. Detection was by 
MS/MS using an Agilent Technologies 1260 Infinity HPLC and an Agilent Technologies 6430 series triple quadrupole mass spectrometer operated in multiple reaction monitoring (MRM) mode. Extracted ion chromatograms for two transitions were used.

A 9-point internal standard-corrected and procedural blank offset calibration curve was determined for each analyte using an extracted spiked matrix method to normalise for recovery and matrix effects. Aliquots of respective matrix (Table 1) were spiked with analyte mass to each calibration level then extracted using respective methods and used for calibration. Detailed calibration information is provided in Wilkinson et al. (2017b) Section 4.0, the complementary Data in Brief article for this work.

Quantification of target analytes in water occurred as part of a separate investigation (Wilkinson et al., 2017a). Here, water samples were collected at the exact locations as studied biota over 4 separate occasions during the same study period and a summary of these concentrations can be found in Table 3 and Wilkinson et al. (2017b) Table 2.

\subsection{Calculation of bioconcentration factors (BCF) and biota-sediment accumulation factors (BSAF)}

BCF (Equation 1) and BSAF (Equation 2) values were calculated based on that described by Arnot and Gobas (2006). Bioaccumulation was classified using three categories: 'not bioaccumulative,' 'bioaccumulative' and 'very bioaccumulative.' Classifications were selected based upon criteria established by four government guidelines/acts (Table 2): 1) the Canadian Environmental Protection Act (Government of Canada, 1999); 2) the Registration, Evaluation and Authorization of Chemicals (REACH) Annexe XII (European Commission, 2001); 3) the United States Environmental Protection Agency (EPA) Toxic Substances Control Act (USEPA, 1976) and 4) the Stockholm Convention on Persistent Organic Pollutants (UNEP, 2001). A bioaccumulative BCF was considered a log value between $3.0(1000 \mathrm{~L} / \mathrm{kg})$ and $3.7(5000 \mathrm{~L} / \mathrm{kg})$ while a 'very bioaccumulative' log BCF value was considered anything $\geq 3.7(5000 \mathrm{~L} / \mathrm{kg})$.

Equation 1: $\quad \mathrm{BCF}=\mathrm{C}_{\text {biota }} / \mathrm{C}_{\text {water }}$ 
Where $\mathrm{C}_{\text {biota }}=$ analyte concentration in the respective matrix and $\mathrm{C}_{\text {water }}=$ analyte concentration in the water

Equation 2: $\quad \mathrm{BSAF}=\mathrm{C}_{\text {biota }} / \mathrm{C}_{\text {sediment }}$

Where $C_{\text {biota }}=$ analyte concentration in the respective biota matrix and $\mathrm{C}_{\text {sediment }}=$ analyte concentration in the sediment

Concentrations of studied analytes in the dissolved-phase of studied water $\left(C_{\text {water }}\right)$ were determined at the same time and at the same locations that all biota samples were collected as part of a concurrent study (Wilkinson et al., 2017a).

\subsection{Results and Discussion}

\subsection{Accumulation and spatial distribution of studied contaminants in sediment}

Ten of thirteen analytes were detected in sediment samples (Table 3 ) with frequencies ranging from 22-83\% (benzoylecgonine and BPA respectively) and mean quantifiable concentrations ranging from 0.84-11.1 $\mathrm{ng} / \mathrm{g}$ dry weight ( $\mathrm{dw}$ ) (BPS and BPA respectively). Concentrations of contaminant accumulation in sediment were near the upper range of those reported elsewhere across Europe for PFCs and plasticiser BPA (e.g., SalgueiroGonzalez et al., 2015 and Becanova et al., 2016) however were generally lower for pharmaceuticals (e.g., Ferreira da Silva et al., 2011). These differences were likely due to the dominance of PFCs and plasticisers in the above-flowing water of all rivers studied in this work (see Wilkinson et al., 2017b, Table 2). Analytes detected in sediment were almost exclusively dominated by plasticisers and perfluorinated compounds. Of the illicit drugs and pharmaceuticals, only benzoylecgonine and diclofenac were detected in sediment above respective LOQs (up to 1.27 and $6.14 \mathrm{ng} / \mathrm{g} \mathrm{dw}$ sediment respectively).

For perfluorinated compounds, a pKa $<1$ and log Kow $>5$ was associated with increased accumulation in sediment. Interestingly, an opposite trend was observed for plasticisers where pKa $>8$ and log Kow $<3$ was associated with greater accumulation in sediment. Although speculative, this difference may be partly influenced by chemical structure. Here, 
longer changed (>C7) amphipathic PFCs appear to be more accumulative than shorter chained PFCs and aromatic plasticisers. A positive association between chain length and PFC sediment accumulation has, in addition to here, been previously described including a particularly high prevalence of PFOS in sediment (e.g., Becanova et al., 2016; Lam et al., 2016).

Organic content as measured by loss-on-ignition (Table 3) of the studied sediment was low (mean $2.32 \% \pm 1.33 \%$ ) and lowest concentrations of accumulated contaminants were generally found in sediment with lowest organic content, particularly in the Hogsmill River (see Section 5 in Wilkinson et al., 2017b).

Among studied compounds detected in sediment, field-based sediment-water distribution coefficients (Kd) ranged from 24.0 to $1200 \mathrm{~L} / \mathrm{Kg}$ ( $\log 1.38$ and 3.08) for acetaminophen and PFOS respectively. Distribution coefficients were in-line with those described elsewhere (e.g., Kwadijk et al., 2010). Overall, long chain (>C7) PFCs PFOS and PFNA showed the highest partition coefficients (Table 4). PFOS was almost exclusively detected in sediment. Of the other studied compounds, less than $20 \%$ of detected target contaminants distributed to sediment ( $\log \mathrm{Kd}<2)$.

The spatial distribution of studied contaminants in river sediment followed a clear pattern dominated by concentrations of plasticisers and perfluorinated compounds (Figure 1a). Among mean concentrations, lowest contaminant levels were observed in river headwater sediment followed by mean concentrations upstream of respective STW effluent outfalls. Highest mean concentrations of all studied contaminants were detected $50 \mathrm{~m}$ downstream from the STW effluent outfall sites and concentrations attenuated with increasing distance from outfall discharge sites (Figure 1a). Here, STW effluent discharges are indicated as a source of the studied contaminants (particularly plasticisers and PFCs) detected in river sediment. It is worth noting that this trend was also observed for the same contaminants dissolved in river water collected at the same locations (see: Wilkinson et al., 2017a).

Between studied rivers, highest concentrations of target analytes (particularly PFCs) were detected in the last $8 \mathrm{~km}$ of the Blackwater River (furthest downstream section of the study 
area). It should be noted that this section of the Blackwater River is located downstream of a military facility. Military bases have previously been indicated as sources of PFCs via their use in aqueous film-forming foams (De Solla et al., 2012; Anderson et al., 2016) and their uses, both historical and present, have been linked to concentrations of PFCs in nearby surface water (Filipovic et al., 2015).

\subsection{Bioaccumulation, transformation and spatial distribution of PPCPs/ECs in aquatic plants}

Unlike PPCP/EC accumulation in sediment and aquatic organisms such as fish, bioaccumulation of PPCPs in primary producers is not well-understood (Du et al., 2015). Here, bioaccumulation of selected aquatic contaminants was specifically assessed up and downstream of STW effluent outfalls in two aquatic plants, Callitriche sp. and Potamogeton sp.

Detection frequencies ranged from $12.5 \%$ to $100 \%$ for acetaminophen and hydroxyacetophenone (HAP), BPS, PFBS and PFOA respectively in Callitriche sp. and 14.3 to $100 \%$ for acetominophen and HAP respectively in Potamogeton sp. (Table 5). Concentrations in both plant species were almost exclusively dominated by plasticisers and perfluorinated compounds, particularly long chain (C>7) PFCs. Of the studied illicit drugs and pharmaceuticals, only acetaminophen and diclofenac were detected in Callitriche sp. up to maximum concentrations of 1.02 and $1.67 \mathrm{ng} / \mathrm{g} \mathrm{dw}$ respectively and acetaminophen and benzoylecgonine up to 2.61 and $3.54 \mathrm{ng} / \mathrm{g} \mathrm{dw}$ respectively in Potamogeton sp. Here, the presence of respective contaminant in each plant appeared most linked to the mean concentration of respective contaminant in the above-flowing water (see Table 2 in Wilkinson et al., 2017b). Both mean detection frequencies and concentrations of plasticisers and PFCs in the aquatic plants were higher in Callitriche sp. than Potamogeton sp. In Callitriche sp., PFOA and PFOS dominated contaminant concentrations with PFOA up to 160 $\mathrm{ng} / \mathrm{g} d \mathrm{w}$ and PFOS up to $284 \mathrm{ng} / \mathrm{g}$ dw respectively (Table 5). 
Unlike the sediment and water collected in the same locations, no level of BPA was observed above the LOQ in any plant sample. Interestingly, elevated concentrations of the BPA-transformation product hydroxyacetophenone (HAP) were detected in both plants at mean concentrations 6.1 times and 12.3 times higher than any other plasticiser in Callitriche sp. and Potamogeton sp. respectively. Although not conclusive, absence of the parent compound BPA and highly elevated concentrations of its transformation product HAP may indicate that both Callitriche sp. and Potamogeton sp. effectively degrade or eliminate the BPA to which they are exposed in the environment. Evidence suggests that such metabolism may be mediated in plants by Cytochrome p450 with contaminants being internalised into the cellular vacuole via protonmotive force generated by vacuolar proton pumps (Kretzschmar et al., 2011). Further quantification of BPA and HAP is warranted within specific plant tissues such as roots, stems and leaves individually where such proton pumps and vacuoles are differentially expressed (Kretzschmar et al., 2011). Phytoremediation has been indicated to degrade pharmaceuticals in aqueous solution and sediment such as metformin into its main transformation products (e.g., Cui and Schroder, 2016). Here, bioaccumulation of the Type 2 Diabetes pharmaceutical metformin was highest in the roots and lowest in the leaves of Typha latifoila (Cui and Schroder, 2016). Additional evidence is needed to determine whether Callitriche sp. and Potamogeton sp. may be similarly effective in the breakdown of BPA into HAP.

The spatial distribution of contaminants accumulated in Potamogeton sp. was marked by a significant increase of both plasticisers (HAP and BPS) and PFCs in the samples collected 50 $\mathrm{m}$ downstream of respective STW effluent discharges. Interestingly, concentrations of plasticiser BPS and the BPA biodegradation product HAP in Potamogeton sp. collected 1000 $\mathrm{m}$ downstream of the STW discharge points were similar to concentrations observed upstream of the discharge, unlike those collected just $50 \mathrm{~m}$ downstream (Figure 1b). Although speculative, this may indicate that the studied plasticisers are rapidly taken up by plants (i.e., within the first 750 m downstream of effluent discharge points). However, in the same plant samples collected $1000 \mathrm{~m}$ downstream from the STW discharge point, concentrations of PFCs (dominated by PFOS) increased by $194 \%$ over those detected $50 \mathrm{~m}$ downstream of the discharge point. PFCs such as PFOS can be formed in the degradation of 
many PFCs, including perfluoroinated sulfonamide alcohol precursors (Chen et al., 2016). Thus, differential uptake by plants may be a result of changing PFC concentrations in the above-flowing water (or sediment) raising from the degradation of PFC precursor compounds (e.g., fluorotelomer alcohols).

The spatial-distribution of PFC concentrations in Callitriche sp. (Figure 1c) were consistent in subsequent samples downstream of respective STW effluent outfalls and only slightly increased (mean 8.8\%) from upstream concentrations. However, plasticisers (dominated by HAP) were found at highest concentrations upstream of the STW discharge point and decreased 2.9 times in concentration between $50 \mathrm{~m}$ and $1000 \mathrm{~m}$ downstream from the STW discharge. Although speculative, such a pattern may be demonstrated by the dilution of plasticiser concentrations by STW effluent (i.e., upstream concentrations of HAP and BPA higher than those in the effluent and hence downstream river flow).

\subsection{Bioaccumulation in periphyton (biofilm)}

The uptake and accumulation of PPCPs/ECs in primary producers such as river biofilm/periphyton is under-studied and not well-understood (Du et al., 2015; Huerta et al., 2016). Previous laboratory-based study demonstrates that biofilms do accumulate some emerging contaminants and a higher log $\mathrm{K}_{\mathrm{ow}}$ is linearly correlated to increased contaminant accumulation (Headley et al., 1998). However, field-based biofilm PPCP/EC bioaccumulation studies remain rare (Huerta et al., 2016).

Here, eight of thirteen contaminants were detected above respective limits of quantification (Table 6) with detection frequencies ranging from 20\% (BPS) to 100\% (diclofenac, BPA, HAP, PFNA and PFOS). Contaminant concentrations were lowest for the pharmaceuticals where only diclofenac was identified up to $4.4 \mathrm{ng} / \mathrm{g} \mathrm{dw}$ biofilm (mean $2.1 \mathrm{ng} / \mathrm{g}$ ). Plasticisers and PFCs dominated both detection frequencies and the concentrations of contaminants found in biofilm (Table 6). BPA and PFOS were detected at the highest concentrations of any of the studied contaminants up to $12.4 \mathrm{ng} / \mathrm{g}$ and $21.7 \mathrm{ng} / \mathrm{g} \mathrm{dw}$ biofilm respectively (mean of 8.27 $\mathrm{ng} / \mathrm{g}$ and $12.6 \mathrm{ng} / \mathrm{g} \mathrm{dw}$ respectively). No illicit drug residue was detected in any collected biofilm sample. 
The amount of pharmaceutical accumulation in river biofilm determined in this work was lower than that presented in Spain by Huerta et al. (2016) but on the same order of magnitude of those detected in Texas by Du et al. (2015). For example, concentrations of diclofenac were quantified in 4 four biofilm samples by Huerta et al. (2016) between <4.63 $\mathrm{ng} / \mathrm{g}$ to $105 \mathrm{ng} / \mathrm{g}$ biofilm. However, it should be noted that Huerta et al. (2016) only measured contaminant concentrations in water once. One-off sampling makes an accurate estimate of water-biofilm distribution coefficients difficult as the biofilm was exposed to a long period of potentially variable concentrations of respective compounds. In the work presented in this paper, water concentrations were sampled four times at each collection point over the study period in a concurrent investigation (Wilkinson et al., 2017a). To the knowledge of the authors, this is among, if not the first assessment of plasticiser, PFC and illicit drug accumulation in river biofilms.

\subsection{Bioaccumulation in benthic organisms}

Despite evidence that pharmaceuticals and emerging contaminants may accumulate in fish, contaminant bioaccumulation in lower trophic-level consumers such as snails and amphipod crustaceans is limited (Du et al., 2015). Recent evidence suggests that pharmaceuticals accumulate in both aquatic snails (Du et al., 2015) and the amphipod crustacean Gammarus pluex (Miller et al., 2015). However, bioaccumulation of contaminants such as illicit drugs, plasticisers and PFCs in aquatic snails and amphipod crustaceans is not well-established in the natural environment.

Seven of thirteen studied contaminants were detected in G. pluex while nine of thirteen were detected in $B$. tentaculata above respective limits of quantification. Mean concentrations ranged from $0.5 \mathrm{ng} / \mathrm{g}$ dry weight $(\mathrm{dw})$ to $14.2 \mathrm{ng} / \mathrm{g} \mathrm{dw}$ (acetaminophen and PFNA respectively) in G. pluex and $0.7 \mathrm{ng} / \mathrm{g} \mathrm{dw}$ to $25.8 \mathrm{ng} / \mathrm{g} \mathrm{dw}$ (acetaminophen and PFBS respectively) in B. tentaculata (Table 7). Detection frequencies in G. pluex ranged from $29 \%$ (acetaminophen, hydroxyacetophenone and BPA) to 100\% (PFBS and PFOA) and 25\% (benzoylecgonine) to $100 \%$ (PFNA and PFOA) in B. tentaculata (Table 7). 
The spatial distribution of contaminants accumulated in snails (B. tentaculata) was characterized by an increase (mean concentrations as much as 10.5 times higher for plasticisers) in concentrations of every contaminant class detected in snails found $50 \mathrm{~m}$ downstream from respective STW effluent outfalls (Figure 1d). Pharmaceuticals and illicit drugs were only detected in snails collected downstream from respective STW effluent outfalls. Concentrations of all studied compounds decreased in snails with increasing collection distance from the STW effluent discharge point. A similar pattern was determined for the spatial distribution of contaminant concentrations found in $G$. pluex, except for concentrations of PFCs (Figure 1e). Interestingly, although concentrations of plasticisers (dominated by BPA) remained relatively constant downstream of respective STW discharges while pharmaceuticals and illicit drug concentrations increased, mean concentrations of PFCs decreased. Here, concentrations of PFCs (dominated by PFBS) in G. pluex collected 50 $\mathrm{m}$ downstream of respective STW effluent discharge points were, on average, $36 \%$ lower than those in G. pluex collected upstream of respective STW discharge points ( $\sum$ PCSs $=21.7$ $\mathrm{ng} / \mathrm{g} \mathrm{dw}$ collected $50 \mathrm{~m}$ downstream vs. $\sum$ PCSs $33.8 \mathrm{ng} / \mathrm{g} \mathrm{dw}$ upstream). This was then followed by a two-fold increase in mean SPFC concentration found in G. pluex collected 1000 m downstream of respective STW effluent discharge points. Although speculative, this pattern may be explained by an initial dilution of PFC concentrations in river water downstream of the STW discharge point (i.e., PFCs concentrations being higher upstream of the STW than in the effluent itself) followed by the breakdown of perfluorinated precursors such as fluorotelomer alcohols into these target compounds between the discharge point and $1000 \mathrm{~m}$ downstream. However, it should be noted that this explanation is speculative and warrants further investigation.

Although only examining bioaccumulation of pharmaceuticals, similar concentrations have recently been reported of other organic contaminants in G. pluex collected from rivers in the same geographical area as those selected here (Miller et al., 2015). Furthermore, similar pharmaceutical-only bioaccumulation study conducted with aquatic snails Planorbid sp. in the North Bosque River, Texas, revealed concentrations and accumulation factors in the same order of magnitude as those reported here (Du et al., 2015). It should be noted that to the knowledge of the authors, this is among, if not the first study examining the spatial distribution and concentrations of pharmaceuticals, illicit drugs, plasticisers and PFCs in G. 
pluex and B. tentaculata hence, accurate and reliable comparison with other work is not readily possible.

\subsection{Classification of field-derived bioconcentration factors (BCF) and biota- sediment accumulation factors (BSAF)}

Of mean log BCFs (Table 4), a total of twelve 'bioaccumulative' (log BCF > 3.0) values were determined, all of which being for plasticisers and PFCs including PFOS (in sediment and Potamogeton sp.), hydroxyacetophenone (in Potamogeton sp. and Callitriche sp.), BPS (in Potamogeton sp. and Callitriche sp.), PFBS (in Callitriche sp. and B. tentaculata), PFOA (in Callitriche sp.) and PFNA (in biofilm, G. pluex and B. tentaculata). Only PFOS in the aquatic plant Callitriche sp. showed a mean log BCF value classified as 'very bioaccumulative' (Figure 2). Interestingly, of the studied plasticisers, BPS and hydroxyacetophenone (breakdown product of BPA) were only found to be bioaccumulative in the studied aquatic plants and not in any other biota.

Mean field-derived log-bioconcentration factors for the water-benthic organism interface (log BCF) ranged from 1.12 to 3.30 (diclofenac and PFNA respectively) in B. tentaculata and 1.66 to 3.62 (benzoylecgonine and PFNA respectively) in G. pluex (Table 4). Mean biotasediment accumulation factor-values (BSAF) were higher for the benthic organisms than those calculated for the water-biota interface, potentially indicating that bioaccumulation of studied contaminants occurs more significantly through sediment than water. Log-BSAF values ranged from 1.70 to 3.56 (BPA and PFNA respectively) for G. pluex and 2.29 to 3.52 (hydroxyacetophenone and BPS respectively) for B. tentaculata (Table 4). A positive relationship was determined between contaminant Kow-values and log BCF where compounds with a Kow-value $>5$ showed the highest log BCF and log BSAF values. Log BCF values were, on average, lower for $G$. pluex than B. tentaculata (0.96 vs 1.63 respectively). Here, differences may be explained by the physiological adaptation of $B$. tentaculata to feed via both scraping and filter feeding, hence exposing the organism to concentrations of contaminants in both detritus and in water or bound to suspended particulate material. 
For biofilm/periphyton, field-based water-biota bioconcentration factors (BCFs) for detected compounds ranged from $12.3 \mathrm{~L} / \mathrm{kg}$ (log-value 1.09) for benzoylecgonine to $1450 \mathrm{~L} / \mathrm{kg}$ (logvalue 3.16) for PFNA (Table 4). Here, only PFNA classifies as 'bioaccumulative' using guidelines established under the US Environmental Protection Agency (USEPA) Toxic Substances Control Act (TSCA) and the Toxic Release Inventory (TRI).

In general, BSAF-values (Table 4) were higher than BCF-values in this work (Figure 3) indicating that either sediment concentrations are simply too low in these study areas compared to those in the water for accurate estimation or that uptake in plants and benthic organisms is more significant via the sediment than the water. Interestingly, while accumulation factors from the biota-sediment interface in G. Pluex and B. Tentaculata are generally within 1 log-unit from each other, those generated from the biota-water interface were much more variable. Here, accumulation factors of PFCs were comparable (within 0.5 log-unit) between the water and sediment interfaces while those determined for plasticisers, pharmaceuticals and illicit drugs were generally at least 1 log-unit lower in the biota-water interface. This finding may indicate that uptake of PPCPs/ECs by benthic amphipods via water may occur by more complicated and physiochemically-dominated mechanisms than in aquatic plants and biofilm/ Periphyton. Such mechanisms may be related to routes of uptake and depuration in benthic amphipods which are not present in plants and should be further investigated.

\subsection{Conclusions}

Here a standardised approach to the development and optimisation of ultrasonic-assisted solvent extraction methodologies was presented and used to establish methods for extractions of PPCPs/ECs from sediment, plants, biofilm/Periphyton and benthic organisms. This optimisation methodology may be applied to develop extraction protocols from other environmental matrices.

Residues of extracted PPCPs/ECs were found in all studied sediment and biota indicating that these emerging contaminants may be classified as ubiquitous in river environments. Concentrations of contaminants were generally higher in biota than sediment, possibly due 
to the low organic content in the studied sediment. A positive association between Kow and contaminant accumulation was observed in this work. Similarly, a positive association was also observed between PFC chain length and accumulation in both sediment and biota where increased chain length correlated with increased accumulation.

Only PFCs, plasticisers and the BPA transformation product HAP were classified as either bioaccumulative or very bioaccumulative. The highest mean log BCF recorded in this work was for PFOS in the aquatic plant Callitriche sp. indicating the contaminant is very bioaccumulative. BSAF-values were generally higher than BCF values potentially indicating that accumulation via sediment is more significant than via water. Contaminants appeared to be differentially bioaccumulative in different biota, indicating there may be a need for a species-specific BCF/BSAF classification system. Such a finding has recently been demonstrated elsewhere (e.g., Lagesson et al., 2016) indicating further research is warranted.

To conclude, future work may focus on establishing and/or modelling the contaminant uptake and transformation mechanisms in aquatic biota. Here, evidence was presented indicating the breakdown of BPA into HAP by both Callitriche sp. and Potamogeton sp. however, this mechanism is not well-characterised. Furthermore, future work (see the Data in Brief article for this work, Wilkinson et al., 2017b, for further future direction) may aim to use well-calibrated passive samplers to more accurately calculate field-derived BCF-values.

Acknowledgements: We thank Kingston University London for funding this work in the form of a bursary.

\section{References}

Albero, B., Sánchez-Brunete, C., García-Valcárcel, A.I., Pérez, R.A. and Tadeo, J.L., 2015. Ultrasound-assisted extraction of emerging contaminants from environmental samples. TrAC Trends in Analytical Chemistry, 71, pp.110-118.

Anderson, R.H., Long, G.C., Porter, R.C. and Anderson, J.K., 2016. Occurrence of select perfluoroalkyl substances at US Air Force aqueous film-forming foam release sites other than fire-training areas: Field-validation of critical fate and transport properties. Chemosphere, 150, pp.678-685. 
Arnot, J.A. and Gobas, F.A., 2006. A review of bioconcentration factor (BCF) and bioaccumulation factor (BAF) assessments for organic chemicals in aquatic organisms. Environmental Reviews, 14(4), pp.257-297.

Bečanová, J., Komprdová, K., Vrana, B. and Klánová, J., 2016. Annual dynamics of perfluorinated compounds in sediment: A case study in the Morava River in Zlín district, Czech Republic. Chemosphere, 151, pp.225-233.

Chen, J., Wang, X., Ge, X., Wang, D., Wang, T., Zhang, L., Tanguay, R.L., Simonich, M., Huang, C. and Dong, Q., 2016. Chronic perfluorooctanesulphonic acid (PFOS) exposure produces estrogenic effects in zebrafish. Environmental Pollution, 218, pp.702-708.

Cui, H. and Schröder, P., 2016. Uptake, translocation and possible biodegradation of the antidiabetic agent metformin by hydroponically grown Typha latifolia. Journal of hazardous materials, 308, pp.355-361.

De Solla, S.R., De Silva, A.O. and Letcher, R.J., 2012. Highly elevated levels of perfluorooctane sulfonate and other perfluorinated acids found in biota and surface water downstream of an international airport, Hamilton, Ontario, Canada. Environment international, 39(1), pp.19-26.

Du, B., Haddad, S.P., Scott, W.C., Chambliss, C.K. and Brooks, B.W., 2015. Pharmaceutical bioaccumulation by periphyton and snails in an effluent-dependent stream during an extreme drought. Chemosphere, 119, pp.927-934.

European Commission. 2001. Strategy for a future chemicals policy. White Paper. European Commission, Brussels, BE. pp. 32.

Filipovic, M., Woldegiorgis, A., Norström, K., Bibi, M., Lindberg, M. and Österås, A.H., 2015. Historical usage of aqueous film forming foam: a case study of the widespread distribution of perfluoroalkyl acids from a military airport to groundwater, lakes, soils and fish. Chemosphere, 129, pp.39-45.

Government of Canada. 1999. Canadian Environmental Protection Act, 1999. Canada Gazette Part III. 22. Public Works and Government Services, Canada, Ottawa, Ont., Canada. pp. 249.

Headley, J.V., Gandrass, J., Kuballa, J., Peru, K.M. and Gong, Y., 1998. Rates of sorption and partitioning of contaminants in river biofilm. Environmental science \& technology, 32(24), pp.3968-3973.

Heiri, O., Lotter, A.F. and Lemcke, G., 2001. Loss on ignition as a method for estimating organic and carbonate content in sediments: reproducibility and comparability of results. Journal of paleolimnology, 25(1), pp.101-110. 
Huerta, B., Rodriguez-Mozaz, S., Nannou, C., Nakis, L., Ruhí, A., Acuña, V., Sabater, S. and Barcelo, D., 2016. Determination of a broad spectrum of pharmaceuticals and endocrine disruptors in biofilm from a waste water treatment plant-impacted river. Science of the Total Environment, 540, pp.241-249.

Jiang, J.J., Lee, C.L., Fang, M.D., Tu, B.W. and Liang, Y.J., 2014. Impacts of emerging contaminants on surrounding aquatic environment from a youth festival. Environmental science \& technology, 49(2), pp.792-799.

Jokinen, E.H., 1992. The freshwater snails (mollusca: gastropoda) of New York State. University of the State of New York, State Education Dept., New York State Museum, Biological Survey, p. 112.

Kretzschmar, T., Burla, B., Lee, Y., Martinoia, E. and Nagy, R., 2011. Functions of ABC transporters in plants. Essays in biochemistry, 50, pp.145-160.

Kwadijk, C.J.A.F., Korytar, P. and Koelmans, A.A., 2010. Distribution of perfluorinated compounds in aquatic systems in the Netherlands. Environmental science \& technology, 44(10), pp.3746-3751.

Lagesson, A., Fahlman, J., Brodin, T., Fick, J., Jonsson, M., Byström, P. and Klaminder, J., 2016. Bioaccumulation of five pharmaceuticals at multiple trophic levels in an aquatic food web-Insights from a field experiment. Science of the Total Environment, 568, pp.208-215.

Lam, N.H., Cho, C.R., Kannan, K. and Cho, H.S., 2016. A nationwide survey of perfluorinated alkyl substances in waters, sediment and biota collected from aquatic environment in Vietnam: Distributions and bioconcentration profiles. Journal of hazardous materials, 223, pp.116-127.

Martín, J., Santos, J.L., Aparicio, I. and Alonso, E., 2010. Multi-residue method for the analysis of pharmaceutical compounds in sewage sludge, compost and sediments by sonication-assisted extraction and LC determination. Journal of separation science, 33(12), pp.1760-1766.

Miller, T.H., McEneff, G.L., Brown, R.J., Owen, S.F., Bury, N.R. and Barron, L.P., 2015. Pharmaceuticals in the freshwater invertebrate, Gammarus pulex, determined using pulverised liquid extraction, solid phase extraction and liquid chromatography-tandem mass spectrometry. Science of the Total Environment, 511, pp.153-160.

Mostofa, K.M., Yoshioka, T., Mottaleb, A. and Vione, D. eds., 2012. Photobiogeochemistry of organic matter: principles and practices in water environments. Springer Science \& Business Media.

Picó, Y. (2013). Ultrasound-assisted extraction for food and environmental samples. TrAC Trends in Analytical Chemistry, 43, 84-99. 
Salgueiro-Gonzalez, N., Turnes-Carou, I., Besada, V., Muniategui-Lorenzo, S., Lopez-Mahia, P. and Prada-Rodriguez, D., 2015. Occurrence, distribution and bioaccumulation of endocrine disrupting compounds in water, sediment and biota samples from a European river basin. Science of the Total Environment, 529, pp.121-130.

Smital, T., Luckenbach, T., Sauerborn, R., Hamdoun, A.M., Vega, R.L. and Epel, D., 2004. Emerging contaminants-pesticides, PPCPs, microbial degradation products and natural substances as inhibitors of multixenobiotic defense in aquatic organisms. Mutation Research/Fundamental and Molecular Mechanisms of Mutagenesis, 552(1), pp.101-117.

UNEP. 2001. Final act of the conference of plenipotentiaries on the Stockholm convention on persistent organic pollutants. In Proceeding of the Conference of Plenipotentiaries on the Stockholm Convention on Persistent Organic Pollutants, Stockholm, Sweden, 22-23 May 2001. United Nations Environment Programme. Available from <http://www.pops.int/documents/meetings/dipcon/25june2001/conf4_finalact/en/FINALA CT-English.PDF>.

Wilkinson, J. L., Hooda, P. S., Barker, J., Barton, S., \& Swinden, J. (2016a). Ecotoxic pharmaceuticals, personal care products, and other emerging contaminants: A review of environmental, receptor-mediated, developmental, and epigenetic toxicity with discussion of proposed toxicity to humans. Critical Reviews in Environmental Science and Technology, 46(4), 336-381.

Wilkinson, J., Swinden, J., Hooda, P.S., Barker, J., and Barton, S. (2016b). Markers of Anthropogenic Contamination: A Validated Method for Quantification of Pharmaceuticals, Illicit Drug Metabolites, Perfluorinated Compounds, and Plasticisers in Sewage Treatment Effluent and Rain Runoff, Chemosphere, 159(2016), 638-646.

Wilkinson, J.L., Hooda, P.S., Swinden, J., Barker, J. and Barton, S., 2017a. Spatial distribution of organic contaminants in three rivers of Southern England bound to suspended particulate material and dissolved in water. Science of The Total Environment, 593, pp.487-497.

Wilkinson, J.L., Hooda, P.S., Swinden, J., Barker, J. and Barton, S., 2017b. Extraction optimisation for pharmaceuticals, illicit drugs, plasticisers, perfluorinated compounds and metabolites from river sediment, biofilm, plants and benthic organisms. Data in Brief, submitted.

Xie, Z., Lu, G., Yan, Z., Liu, J., Wang, P. and Wang, Y., 2016. Bioaccumulation and trophic transfer of pharmaceuticals in food webs from a large freshwater lake. Environmental Pollution, 222(2017), 356-366. 


\section{List of Tables}

Table 1: Summary of conditions used for ultrasonic extraction of studied PPCPs/ECs from respective matrices

\begin{tabular}{|c|c|c|c|c|c|}
\hline Matrix & Preparation & $\begin{array}{l}\text { Extraction } \\
\text { Solution }\end{array}$ & $\begin{array}{l}\text { Sample mass } \\
\text { (g) }\end{array}$ & $\begin{array}{l}\text { Temp. } \\
\left({ }^{\circ} \mathrm{C}\right)\end{array}$ & $\begin{array}{c}\text { Mean } \\
\text { Recovery** (\%) }^{\text {Mecol }}\end{array}$ \\
\hline $\begin{array}{l}\text { Amphipod } \\
\text { Crustaceans }\end{array}$ & Freeze dry, powdered & $\begin{array}{c}20 \mathrm{~mL} 75: 25 \\
\text { ACN:MeOH } \\
1 \% \text { acetic acid }\end{array}$ & $\begin{array}{c}\text { Variable* } \\
\text { (mean }=0.34)\end{array}$ & 45 & 67 \\
\hline $\begin{array}{l}\text { Aquatic } \\
\text { Plants }\end{array}$ & Air dry, powdered & $\begin{array}{c}20 \mathrm{~mL} 75: 25 \\
\text { ACN:MeOH } \\
1 \% \text { acetic acid }\end{array}$ & 0.5 & 40 & 81 \\
\hline Biofilm & Air dry, powdered & $\begin{array}{c}20 \mathrm{~mL} 75: 25 \\
\text { ACN:MeOH } \\
1 \% \text { acetic acid }\end{array}$ & $\begin{array}{c}\text { Variable* } \\
\text { (mean }=0.67 \text { ) }\end{array}$ & 45 & 62 \\
\hline $\begin{array}{l}\text { Gastropods } \\
\text { (snails) }\end{array}$ & Freeze dry, powdered & $\begin{array}{c}20 \mathrm{~mL} 75: 25 \\
\text { ACN:MeOH } \\
1 \% \text { acetic acid }\end{array}$ & $\begin{array}{c}\text { Variable* } \\
\text { (mean }=0.35)\end{array}$ & 45 & 67 \\
\hline Sediment & $\begin{array}{l}\text { Air dry, powdered, } \\
\text { sieved to }<750 \mu \mathrm{m}\end{array}$ & $\begin{array}{c}20 \mathrm{~mL} 50: 50 \\
\text { ACN:MeOH } \\
1 \% \text { acetic acid }\end{array}$ & 1.0 & 40 & 76 \\
\hline
\end{tabular}

ACN- acetonitrile

$\mathrm{MeOH}$ - methanol

* Sample mass depended on the mass of sampled organisms (all collected material from each sample point was extracted)

** Spiked matrix recovery at $100 \mathrm{ng} / \mathrm{g}(\mathrm{n}=3)$ 
Table 2: Government guidelines on bioconcentration factors (Adapted from: Arnot and Gobas, 2006)

\begin{tabular}{|c|c|c|c|}
\hline Agency & Classification & $\mathrm{BCF}(\mathrm{L} / \mathrm{Kg})$ & Log BCF \\
\hline Environment Canada $^{1}$ & Bioaccumulative & $\geq 5000$ & 3.7 \\
\hline European Union ${ }^{2}$ & Bioaccumulative & $\geq 2000$ & 3.3 \\
\hline European Union ${ }^{2}$ & Very bioaccumulative & $\geq 5000$ & 3.7 \\
\hline $\begin{array}{l}\text { U.S. Environmental Protection } \\
\text { Agency (EPA) }\end{array}$ & Bioaccumulative & $\geq 1000$ & 3.0 \\
\hline U.S. EPA & Very bioaccumulative & $\geq 5000$ & 3.7 \\
\hline $\begin{array}{l}\text { United Nations Environment } \\
\text { Programme (UNEP) }\end{array}$ & Bioaccumulative & $\geq 5000$ & 3.7 \\
\hline
\end{tabular}

${ }^{1}$ Canadian Environmental Protection Act (Government of Canada, 1999)

${ }^{2}$ Registration, Evaluation and Authorization of Chemicals (REACH) Annex XII (European Commission, 2001)

${ }^{3}$ United States Environmental Protection Agency (EPA) Toxic Substances Control Act (TSCA) (USEPA, 1976)

${ }^{4}$ Stockholm Convention on Persistent Organic Pollutants (UNEP, 2001) 
Table 3: Summary of target analytes extracted from sediment with a river-by-river comparison and loss on ignition results

\begin{tabular}{|c|c|c|c|c|c|c|c|}
\hline \multirow[b]{2}{*}{ Compound Type } & \multirow[b]{2}{*}{ Compound } & \multicolumn{3}{|c|}{ Overall Analysis } & \multicolumn{3}{|c|}{ River-by-river means (ng/g) } \\
\hline & & $\begin{array}{l}\text { Mean } \\
\text { (ng/g) }\end{array}$ & $\begin{array}{l}\text { Range } \\
\text { (ng/g) }\end{array}$ & $\begin{array}{c}\text { Det. Freq. } \\
(\%)\end{array}$ & Blackwater & Bourne & Hogsmil \\
\hline \multirow[t]{3}{*}{ Pharmaceuticals } & Acetominophen & $<L O Q$ & $<0.93-1.11$ & 43.5 & $<\mathrm{LOQ}$ & $<L O Q$ & $<\mathrm{LOQ}$ \\
\hline & Diclofenac & 1.53 & $<0.96-6.14$ & 78.3 & 1.28 & $<L O Q$ & 2.85 \\
\hline & Ethinylestradiol & ND & ND & 0.00 & ND & ND & ND \\
\hline \multirow[t]{3}{*}{ Illicit Drugs } & Amphetamine & 0.43 & $<1.09-3.60$ & 30.4 & $<\mathrm{LOQ}$ & ND & ND \\
\hline & Benzoylecgonine & $<\mathrm{LOQ}$ & $<1.02-1.27$ & 21.7 & $<\mathrm{LOQ}$ & $<\mathrm{LOQ}$ & $<\mathrm{LOQ}$ \\
\hline & Methamphetamine & ND & ND & 0.00 & ND & ND & ND \\
\hline \multirow[t]{3}{*}{ Plasticisers } & BPA & 11.1 & $<3.87-67.1$ & 82.6 & 14.7 & 4.62 & 6.12 \\
\hline & BPS & 0.84 & $<1.09-4.84$ & 69.6 & 0.85 & 1.40 & $<\mathrm{LOQ}$ \\
\hline & HAP & 2.57 & 11.3 & 60.9 & 2.61 & 5.65 & ND \\
\hline \multirow{4}{*}{$\begin{array}{l}\text { Perfluorinated } \\
\text { Compounds }\end{array}$} & PFBS & 3.21 & $<1.13-10.7$ & 56.5 & 3.42 & 6.49 & ND \\
\hline & PFNA & 5.98 & $<0.75-78.6$ & 69.6 & 8.58 & 1.10 & 2.58 \\
\hline & PFOA & 1.70 & $<1.13-15.4$ & 43.5 & 2.61 & $<\mathrm{LOQ}$ & ND \\
\hline & PFOS & 6.16 & $<1.52-25.0$ & 56.5 & 7.89 & 7.82 & ND \\
\hline \multicolumn{2}{|c|}{ Loss on Ignition (\%) } & 2.32 & $1.19-6.36$ & & 2.48 & 2.38 & 1.70 \\
\hline
\end{tabular}


Table 4: Field-derived BCF and BSAF values with log conversions for all studied biota (*ND- not detected, sed-sediment, m-matrix)

\begin{tabular}{|c|c|c|c|c|c|c|c|c|c|c|c|}
\hline \multirow[t]{2}{*}{$\begin{array}{l}\text { Contaminant } \\
\text { Type }\end{array}$} & \multirow[t]{2}{*}{ Contaminant } & \multicolumn{6}{|c|}{$\frac{\text { Bioconcentration Factor, } \mathrm{L} / \mathrm{Kg} \text { (BCF) }}{\text { Biota-Water }}$} & \multicolumn{4}{|c|}{$\frac{\text { Biota-Sediment Accumulation Factor (BSAF) }}{\text { Biota-Sediment }}$} \\
\hline & & Sediment & Potamogeton & Callitriche & Biofilm & B. tentaculata & G. pluex & Potamogeton & Callitriche & B. tentaculata & G. pluex \\
\hline \multirow[t]{3}{*}{ Pharmaceuticals } & Acetominophen & 24.0 & 45.9 & 22.5 & 22.1 & 37.04 & 26.4 & 45.9 & 893 & 869 & 899 \\
\hline & Diclofenac & 83.9 & 3.92 & 8.69 & 213 & 13.29 & 12.9 & 3.92 & 563 & 405 & 445 \\
\hline & Ethinylestradiol & ND & ND & ND & ND & ND & ND & ND & ND & ND & ND \\
\hline \multirow[t]{3}{*}{ Illicit Drugs } & Amphetamine & ND & ND & ND & ND & ND & ND & ND & ND & ND & ND \\
\hline & Benzoylecgonine & 77.0 & 82.2 & ND-M* & 12.3 & 60.98 & 0.02 & 82.2 & ND-M* & 699 & ND-M* \\
\hline & Methamphetamine & ND & ND & ND & ND & ND & ND & ND & ND & ND & ND \\
\hline \multirow[t]{3}{*}{ Plasticisers } & HAP & 61.2 & 1410 & 4320 & 36.2 & 49.42 & 8.44 & 1410 & 44100 & 196 & 783 \\
\hline & BPA & 85.2 & ND-M* & 5.17 & 63.0 & 19.46 & 1.26 & ND-M* & 79.8 & 602 & 50.1 \\
\hline & BPS & 78.4 & 1070 & 2370 & 82.7 & 295.42 & ND-M* & 1070 & 27900 & 3280 & ND-M* \\
\hline Perfluorinated & PFBS & 88.6 & 363 & 1890 & ND-M* & 1426.90 & 320 & 363 & 8430 & 809 & 810 \\
\hline \multirow[t]{4}{*}{ Compounds } & PFNA & 591 & 172 & ND-M* & 1450 & 2001.48 & 4140 & 172 & ND Sed* & 2170 & 3600 \\
\hline & PFOA & 53.5 & 243 & 1140 & 233 & 161.90 & 55.8 & 243 & 23100 & 571 & 571 \\
\hline & PFOS & 1200 & 1330 & 19500 & 659 & 439.82 & 590 & 1320 & 24500 & 2910 & 2910 \\
\hline & & \multicolumn{6}{|c|}{ Log Bioconcentration Factor (log BCF) } & \multicolumn{4}{|c|}{ Log Biota-Sediment Accumulation Factor (log BSAF) } \\
\hline \multirow[t]{3}{*}{ Pharmaceuticals } & Acetominophen & 1.38 & 1.66 & 1.35 & 1.34 & 1.57 & 1.42 & 1.66 & 2.95 & 2.94 & 2.95 \\
\hline & Diclofenac & 1.92 & 0.59 & 0.94 & 2.33 & 1.12 & 1.11 & 0.59 & 2.75 & 2.61 & 2.65 \\
\hline & Ethinylestradiol & ND & ND & ND & ND & ND & ND & ND & ND & ND & ND \\
\hline \multirow[t]{3}{*}{ Illicit Drugs } & Amphetamine & ND & ND & ND & ND & ND & ND & ND & ND & ND & ND \\
\hline & Benzoylecgonine & 1.89 & 1.91 & ND-M* & 1.09 & 1.79 & -1.66 & 1.91 & ND-M* & 2.81 & ND-M* \\
\hline & Methamphetamine & ND & ND & ND & ND & ND & ND & ND & ND & ND & ND \\
\hline \multirow[t]{3}{*}{ Plasticisers } & HAP & 1.79 & 3.15 & 3.64 & 1.56 & 1.69 & 0.93 & 3.15 & 4.64 & 2.29 & 2.89 \\
\hline & BPA & 1.93 & ND-M* & 0.71 & 1.80 & 1.29 & 0.10 & ND-M* & 1.90 & 2.78 & 1.70 \\
\hline & BPS & 1.89 & 3.03 & 3.37 & 1.92 & 2.47 & & 3.03 & 4.45 & 3.52 & ND-M* \\
\hline Perfluorinated & PFBS & 1.95 & 2.56 & 3.28 & ND-M* & 3.15 & 2.50 & 2.56 & 3.93 & 2.91 & 2.91 \\
\hline \multirow[t]{3}{*}{ Compounds } & PFNA & 2.77 & 2.24 & ND-M* & 3.16 & 3.30 & 3.62 & 2.24 & ND in Sed* & 3.34 & 3.56 \\
\hline & PFOA & 1.73 & 2.38 & 3.06 & 2.37 & 2.21 & 1.75 & 2.38 & 4.36 & 2.76 & 2.76 \\
\hline & PFOS & 3.08 & 3.12 & 4.29 & 2.82 & 2.64 & 2.77 & 3.12 & 4.39 & 3.46 & 3.46 \\
\hline
\end{tabular}


Table 5: Concentrations of target contaminants in Callitriche sp. and Potamogeton sp. and basic statistical analysis

\begin{tabular}{|c|c|c|c|c|}
\hline \multirow[b]{2}{*}{ Compound Class } & \multirow[b]{2}{*}{ Compound } & \multicolumn{3}{|c|}{ Callitriche sp.- Water Starwort $(n=8)$} \\
\hline & & Mean (ng/g) & Range (ng/g) & Det. Freq. (\%) \\
\hline \multirow[t]{3}{*}{ Pharmaceuticals } & Acetaminophen & $<\mathrm{LOQ}$ & $<\mathrm{LOQ}$ & 12.5 \\
\hline & Diclofenac & 0.42 & $<\mathrm{LOQ}$ & 62.5 \\
\hline & Ethinylestradiol & ND & ND & 0 \\
\hline Illicit Drugs/ & Benzoylecgonine & ND & ND & 0 \\
\hline \multirow[t]{2}{*}{ Metabolites } & Amphetamine & ND & ND & 0 \\
\hline & Methamphetamine & ND & ND & 0 \\
\hline \multirow[t]{3}{*}{ Plasticisers } & BPA & $<\mathrm{LOQ}$ & ND & 0 \\
\hline & HAP & 87.94 & $<2.08-255$ & 100 \\
\hline & BPS & 14.42 & $<2.18-48.3$ & 100 \\
\hline Perfluorinated & PFBS & 41.3 & $<1.68-64.2$ & 100 \\
\hline \multirow[t]{3}{*}{ Compounds } & PFNA & 12.01 & $<1.11-34.9$ & 62.5 \\
\hline & PFOA & 45.15 & $<1.68-160$ & 100 \\
\hline & PFOS & 112.89 & $<3.04-284$ & 50 \\
\hline & & \multicolumn{3}{|c|}{ Potamogeton sp.- Pondweed $(n=7)$} \\
\hline \multirow[t]{3}{*}{ Pharmaceuticals } & Acetaminophen & 0.38 & $<1.86-2.61$ & 14.3 \\
\hline & Diclofenac & $<\mathrm{LOQ}$ & $<\mathrm{LOQ}$ & 0 \\
\hline & Ethinylestradiol & ND & $<L O Q$ & 0 \\
\hline Illicit Drugs/ & Benzoylecgonine & 0.67 & $<2.04-3.54$ & 28.6 \\
\hline \multirow[t]{2}{*}{ Metabolites } & Amphetamine & ND & ND & 0 \\
\hline & Methamphetamine & ND & ND & 0 \\
\hline \multirow[t]{3}{*}{ Plasticisers } & BPA & $<\mathrm{LOQ}$ & $<\mathrm{LOQ}$ & 0 \\
\hline & HAP & 71.02 & $<2.08-165$ & 100 \\
\hline & BPS & 5.83 & $<2.18-30.5$ & 71.4 \\
\hline Perfluorinated & PFBS & 14.16 & $<1.68-38.9$ & 85.7 \\
\hline \multirow[t]{3}{*}{ Compounds } & PFNA & 8.5 & $<1.11-40.6$ & 71.4 \\
\hline & PFOA & 6.56 & $<1.68-16.5$ & 85.7 \\
\hline & PFOS & 9.83 & $<3.04-68.8$ & 14.3 \\
\hline
\end{tabular}


Table 6: Concentrations of target contaminants in periphyton (biofilm) and basic statistical analysis

\begin{tabular}{|ll|ccc|} 
Compound Type & Compound & Mean (ng/g) & Range (ng/L) & Det. Freq. (\%) \\
\hline Pharmaceuticals & Acetaminophen & ND & ND & ND \\
& Diclofenac & 2.09 & $<1.43-4.40$ & 100 \\
& Ethinylestradiol & ND & ND & ND \\
\cline { 1 - 2 } Illicit Drugs & Amphetamine & ND & ND & ND \\
& Benzoylecgonine & ND & ND & ND \\
& Methamphetamine & ND & ND & ND \\
\cline { 1 - 2 } Plasticisers & BPA & 8.27 & $<5.75-12.4$ & 100 \\
& BPS & 0.56 & $<$ LOQ & 20 \\
& HAP & 3.95 & $<1.55-5.67$ & 100 \\
\cline { 1 - 2 } Perfluorinated & PFBS & ND & ND & ND \\
& PFNA & 2.55 & $<1.11-10.7$ & 100 \\
& PFOA & 4.92 & $<1.68-20.7$ & 80 \\
& PFOS & 12.55 & $<2.26-21.7$ & 100 \\
\hline
\end{tabular}

Table 7: Concentrations of target contaminants in G. pluex and B. tentaculata and basic statistical analysis

\begin{tabular}{|l|l|cc|cc|}
\multirow{3}{*}{ Compound Class } & Compound & $\begin{array}{c}\text { G. Pluex } \\
\text { Mean (ng/g) }\end{array}$ & $\begin{array}{c}\text { B. Tentaculata } \\
\text { Mean (ng/g) }\end{array}$ & $\begin{array}{c}\text { G. pluex } \\
\text { Det. Freq. (\%) }\end{array}$ & $\begin{array}{c}\text { B. tentaculata } \\
\text { Det. Freq. (\%) }\end{array}$ \\
\hline Pharmaceuticals & Acetominophen & 0.5 & 0.7 & 29 & 38 \\
& Diclofenac & 0.7 & 1.4 & 71 & 50 \\
& Ethinylestradiol & ND & ND & 0 & 0 \\
\hline Illicit Drugs/ & Amphetamine & ND & ND & 0 & 0 \\
Metabolites & Benzoylecgonine & ND & 0.9 & 0 & 25 \\
& Methamphetamine & ND & ND & 0 & 0 \\
\hline Plasticisers & HAP & 0.6 & 1.6 & 29 & 38 \\
& Bisphenol-A & $<$ LOQ & 9.5 & 29 & 63 \\
& Bisphenol-S & ND & 5.1 & 0 & 38 \\
\hline Perfluorinated & PFBS & 5.9 & 25.8 & 100 & 88 \\
Compounds & PFNA & 14.2 & 3 & 86 & 100 \\
& PFOA & 1.6 & 6 & 100 & 100 \\
& PFOS & 8.6 & 8.9 & 86 & 75 \\
\hline
\end{tabular}




\section{List of Figures}

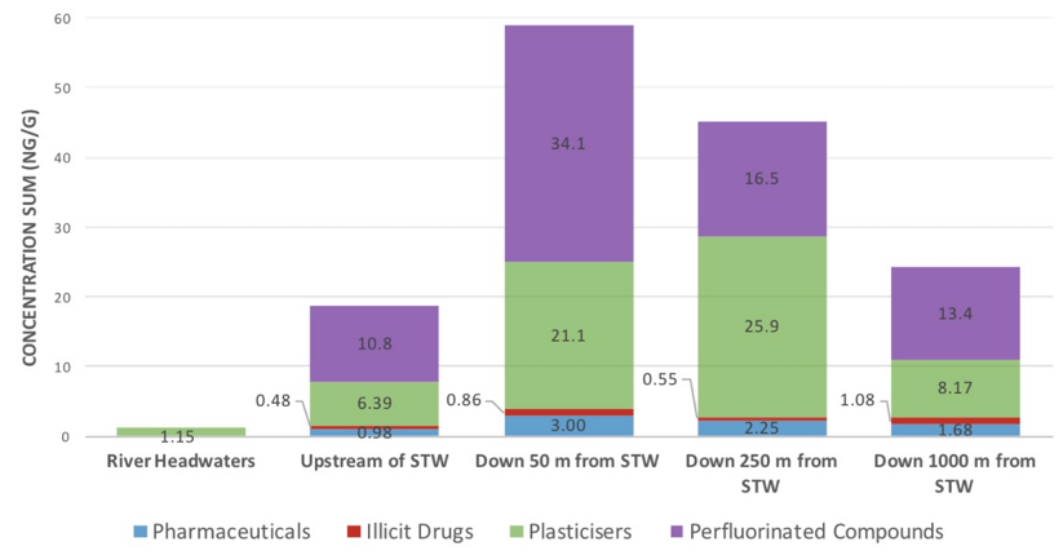

A) Spatial Distribution in Sediment (ng/g dry weight)

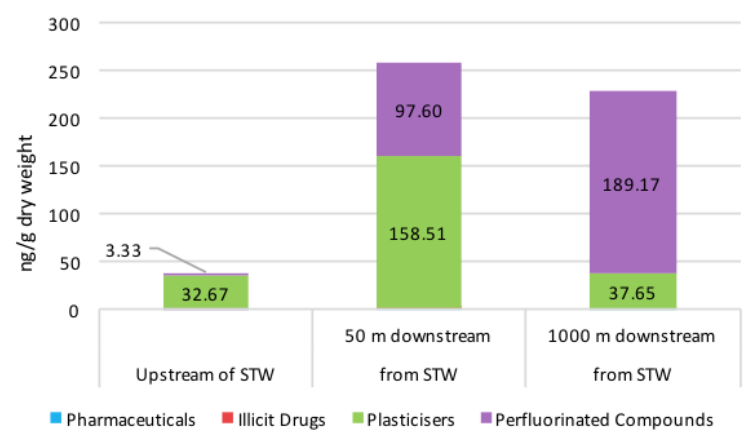

B) Spatial Distribution in Potamogeton sp.

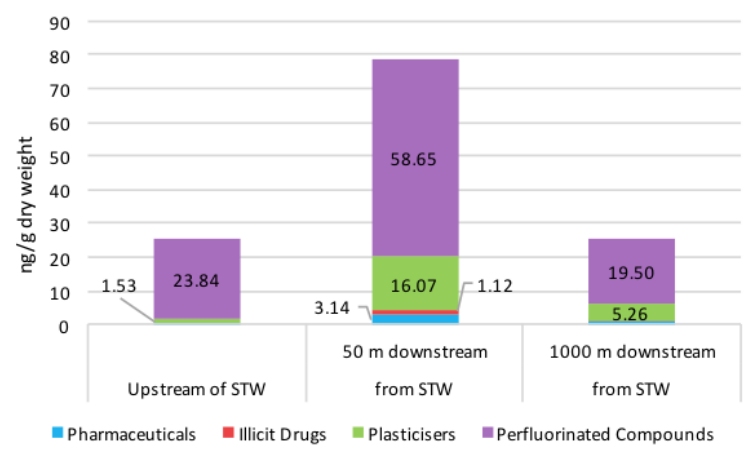

D) Spatial Distribution in Bithynia Tentaculata

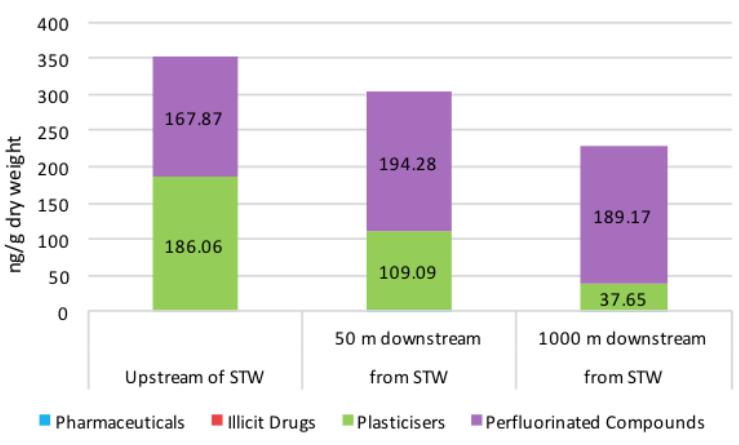

C) Spatial Distribution in Callitriche sp.

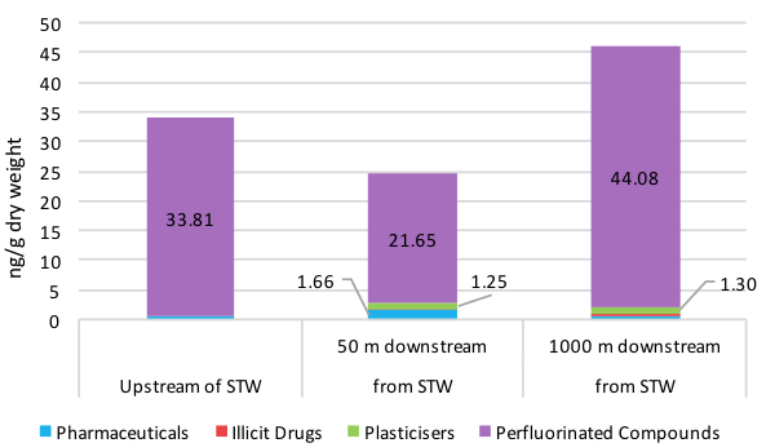

E) Spatial Distribution in Gammarus Pluex

Figure 1: Spatial distribution of target contaminants in studied biota and sediment up- and downstream from sewage treatment works effluent discharge outfalls 


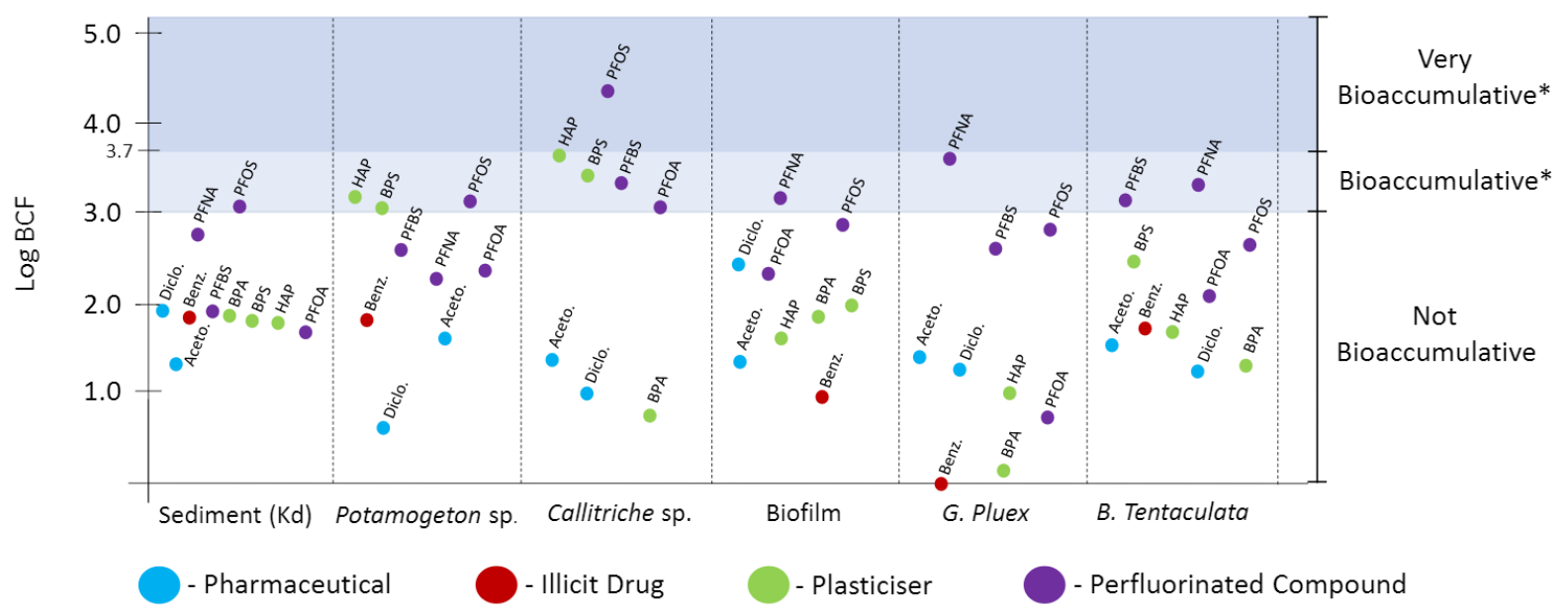

Figure 2: Field-derived distribution coefficient $(\mathrm{Kd})$ and log bioconcentration factors (LogBCF) for sediment, primary producers (biofilm and aquatic plants Potamogeton sp. and Callitriche sp.) and lower trophic-level consumers (amphipod crustacean G. Pluex and aquatic snail $B$. Tentaculata)

*'Bioaccumulative' and 'very bioaccumulative' classifications were set as those established by USA, EU, Canadian and United Nations guidelines. 


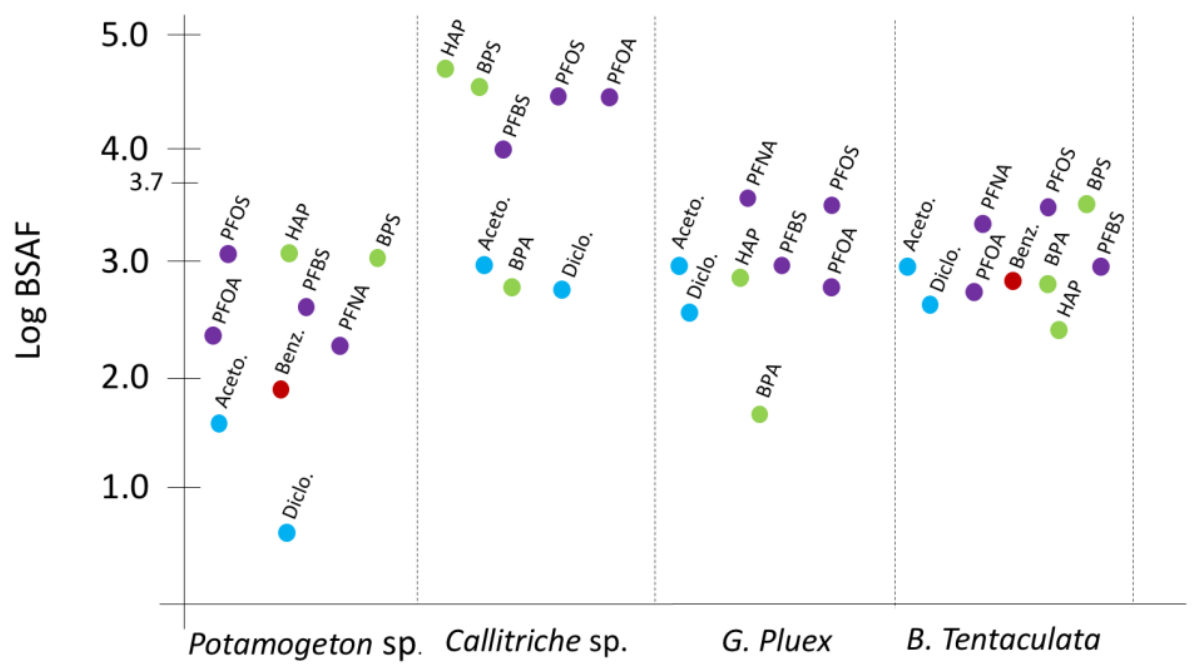

Figure 3: Field-derived log biota-sediment accumulation factors for all studied biota 